\title{
RESISTÊNCIA DE SOJA A INSETOS: VII. AVALIAÇÃO DE DANOS DE PERCEVEJOS EM CULTIVARES E LINHAGENS ( 1 )
}

\author{
ANDRÉ LUIZ LOURENÇĀO $\left({ }^{2}, 5\right)$, MANOEL ALBINO COELHO \\ DE MIRANDA $(3,5)$ e VIOLETA NAGAI $\left({ }^{4,5}\right)$
}

\begin{abstract}
RESUMO
Em dois anos consecutivos (1980/81 e 1981/82) estudou-se, em Campinas, o comportamento de oito linhagens (IAC 73-228, IAC 77-3802, IAC 77-3823, IAC 78-2296, IAC 78-2318, IAC 78-3258, IAC 78-3278 e D72-9601-1) e dois cultivares (Santa Rosa e TMU) de soja em relação ao ataque de percevejos em campo. No primeiro ano, a infestação natural de Nezara viridula (L) e Piezodorus guildinii (West.) foi complementada com liberação de adultos de Euschistus heros (Fabr.) coletados em lavouras de soja. No segundo ano, não houve necessidade de infestaçōes artificiais, já que as populações naturais de $N$. viridula e $P$. guildinii estavam altas. Como critérios para avaliação de dano, usaram-se: retenção foliar, produção de grãos, produção dividida em quatro classes de dano, porcentagem em peso de grãos danificados, peso de cem sementes, teor de óleo e poder germinativo. IAC 73-228 e IAC 78-2318 comportaram-se como os mais resistentes.
\end{abstract}

Termos de indexação: soja; Glycine max (L.) Merrill; resistência varietal a percevejos; Pentatomidae; Nezara viridula (L.); Piezodorus guildinii (West); Euschistus heros (Fabr.)

(1) Trabalho apresentado ao IV Seminário Nacional de Pesquisa de Soja, realizado em Porto Alegre (RS), 8-12 de setembro de 1986. Recebido para publicação em 11 de agosto de 1986. nas (SP).

${ }^{(2)}$ Seçāo de Entomologia Fitotécnica, Instituto Agronômico (IAC), Caixa Postal 28, 13001 Campi-

$\left({ }^{3}\right)$ Seção de Leguminosas, IAC.

(4) Seção de Técnica Experimental e Cálculo, IAC.

$\left({ }^{5}\right)$ Bolsista do CNPq. 


\section{INTRODUÇÃO}

O complexo de pentatomídeos fitófagos presente em lavouras de soja (Glycine max (L.) Merrill) tem sido apontado como o mais nocivo grupo de pragas da cultura em diversas regiōes brasileiras. MIRANDA et al. (1979) relacionaram os danos causados por esses insetos à soja. Para seu controle, esses autores, juntamente com PANIZZl et al. (1981) e ROSSETTO et al. (1986), enfatizaram o uso de cultivares resistentes como o método ideal. Fontes de resistência jå foram identificadas (JONES \& SULLIVAN, 1979; MIRANDA et al., 1979; PANIZZI et al., 1981; GILMAN et al., 1982), e um método de seleção de linhagens resistentes a partir de uma dessas fontes foi apresentado por LOURENÇĀO et al. (1985).

Posteriormente, ROSSETTO et al. (1986) estudaram o comportamento dos principais cultivares plantados em São Paulo, de algumas introduções e de linhagens obtidas do programa de melhoramento de soja visando a resistência a percevejos em relação ao ataque desses insetos; utilizaram como critério para avaliar a resistência, a porcentagem de área foliar retida após a maturaçäo das vagens, o índice porcentual de dano na vagem e a produção, verificando que a linhagem IAC 80-4228 exibiu resistência estável nos dois anos de experimentação.

Todavia, torna-se de interesse saber o comportamento de outras linhagens em pesquisa no IAC ainda não avaliadas diante do ataque de percevejos e, também, estudar características associadas à resistência, o que constituiu o objetivo do presente trabalho.

\section{MATERIAL E MÉTODOS}

As oito linhagens e os dois cultivares estudados, juntamente com suas respectivas origens - Quadro 1 - foram observados em experimento instalado no Centro Experimental de Campinas em dois anos agricolas consecutivos, 1980/81 e $1981 / 82$.

A linhagem D72-9601-1, precoce, é resultante de seleção feita para cor marrom de pubescência dentro de D72-9601, que, por sua vez, foi selecionada nos EUA para resistência a Pseudoplusia includens (Walker). Apenas D72-9601-1 apresenta ciclo mais curto, sendo os nove materiais restantes de ciclo médio. O 'TMU', provavelmente originário da Flóriđa (EUA), foi introduzido na Alta Mojiana por agricultores da região (LOURENÇĀO \& MIRANDA, 1983). A IAC 73-228, linhagem resistente a percevejos (MIRANDA et al., 1979), tem sido utilizada no programa de melhoramento para resistência a esses insetos (LOURENÇĀO et al., 1985). A IAC 78-2318 é uma linhagem pouco atacada pela broca dos ponteiros Epinotia aporema (Wals.) (LOURENÇÃO \& MIRANDA, 1983). As demais linhagens são resultantes do programa de melhoramento desenvolvido pela Seção de Leguminosas do IAC. 
No primeiro ano, o experimento foi plantado a 3-12-1980 e constou de dez tratamentos e oito repetiçōes, com delineamento em blocos ao caso. Cada parcela foi representada por três linhas de $3 \mathrm{~m}$, espaçadas $0,6 \mathrm{~m}$ entre si e separadas da parcela seguinte por uma linha do 'Santa Rosa'. Este cultivar também foi usado como bordadura do ensaio mediante três linhas contínuas. Após a emergência, procedeu-se ao desbaste, procurando-se deixar vinte plantas por metro linear.

Durante os estádios reprodutivos das plantas, observou-se no campo a presença das espécies Piezodorus guildinii (West.) e Nezara viridula (L.), com predominância da primeira; complementando a infestação natural, liberaram-se na área 1.500 individuos de Euschistus heros (Fabr.) coletados em lavouras de soja em Agual, SP.

Por ocasião da completa maturação das vagens, efetuou-se a avaliação da retenção foliar mediante uso da seguinte escala de notas: 1: de 0 a 10\% de plantas com sintomas de retenção foliar, 2: de 11 a 20\%; 3: de 21 a $40 \%$; 4: de 41 a $60 \%$, e 5: de 61 a $100 \%$. Os valores foram convertidos em $\sqrt{x+1}$ e, as médias, comparadas pelo teste de Tukey ao nivel de $5 \%$.

De cada parcela, colheu-se a linha central, considerando as outras duas como bordadura. As pesagens foram convertidas para quilograma/hectare e analisadas, sendo as médias comparadas pelo teste de Tukey a $5 \%$. A seguir, os grãos de cada parcela foram separados em quatro categorias de danos, segundo JENSEN \& NEWSOM (1972): 1: sementes sem danos visiveis; 2: sementes com puncturas, mas sem deformação; 3: sementes com puncturas e com deformação, e 4: sementes totalmente deformadas. O peso dos grãos em cada uma das classes foi analisado e, as médias, comparadas pelo teste de Tukey a $5 \%$. Para obtençāo da porcentagem em peso de grãos danificados, escolheram-se e pesaram-se aqueles que visualmente apresentavam injúrias provenientes do ataque - de percevejos, e calculou-se a porcentagem em relação ao peso total. Das sementes sem danos de cada parcela, separou-se o material para obtenção do indice "peso de cem sementes", cujos dados foram analisados e as médias, comparadas por Tukey a $5 \%$.

A 22-10-81, procedeu-se ao plantio dos mesmos tratamentos, repetindo-se o experimento do ano anterior. Devido a limitaçōes de área, reduziu-se o número de repetiçōes de oito para seis, conservando-se as dimensōes da parcela e da bordadura, e os tratos culturais.

Após o florescimento, verificou-se, como no ano anterior, a presença predominante de $P$. guildinii, sobre $N$. viridula, nas plantas do campo experimental. Não houve necessidade de complementar a infestação natural, bastante intensa nesse campo. 
Com exceção da classificação dos grãos em classes de dano, os critérios usados para avaliação foram os mesmos do ano anterior, ou seja, retenção foliar, produção de grãos, porcentagem em peso de grãos danificados e peso de cem sementes, acrescendo-se porcentagem de lipidios em gráos com e sem ataque e porcentagem de germinação.

Para determinação do teor de óleo, separaram-se amostras de $10 \mathrm{~g}$ tiradas ao acaso de um lote de sementes classes 1 e 2 (sem dano) e $10 \mathrm{~g}$ de um lote de sementes classes 3 e 4 (danificadas) de cada parcela $\left(^{6}\right)$.

A germinação foi avaliada pelas regras de análise de sementes, sendo os valores obtidos transiormados em arco seno $\sqrt{x / 100}$, onde $x$ é a variável expressa em porcentagem, analisados e, as médias, comparadas por Tukey a $5 \%$.

Efetuou-se análise conjunta dos resultados, verificando-se as correlações entre as características estudadas.

\section{RESULTADOS E DISCUSSÃO}

Os resultados da retenção foliar acham-se no quadro 1 . Verifica-se que houve efeito de ano, tendo o segundo experimento (1981/82) média significativamente superior à do primeiro. Uma das causas dessa diferença pode ser a época de semeadura, pois plantios antecipados (setembro-outubro) prolongam o período reprodutivo, fase em que os percevejos provocam danos às plantas. O 'TMU' exibiu no primeiro ano e na média geral a mais alta retenção foliar, sugerindo suscetibilidade, enquanto IAC 73-228 e IAC 78-2318 apresentaram boa maturação nos dois anos. MIRANDA et al. (1979) também observaram baixo indice de retenção foliar em IAC 73-228 quando comparada com 'Paraná', 'Santa Rosa', e 'Viçoja' e duas introduçōes.

IAC 73-228 teve produtividades superiores a $2.000 \mathrm{~kg} / \mathrm{ha}$ nos dois anos (Quadro 2), confirmando dados de MIRANDA et al. (1979) que verificaram que essa é a linhagem de maior produção sob condiçōes de infestação de percevejos. Também com mais de $2.000 \mathrm{~kg} / \mathrm{ha}$ na média geral situaram-se as linhagens IAC 78-3258 e IAC 78-2318, ao passo que D72-9601 teve a menor média.

${ }^{(6)}$ Os autores agradecem ao Engㅇ-Agro João Paulo Feijāo Teixeira, da Seção de Fitoqulmica do Instituto Agronômico, a realização das análises. 


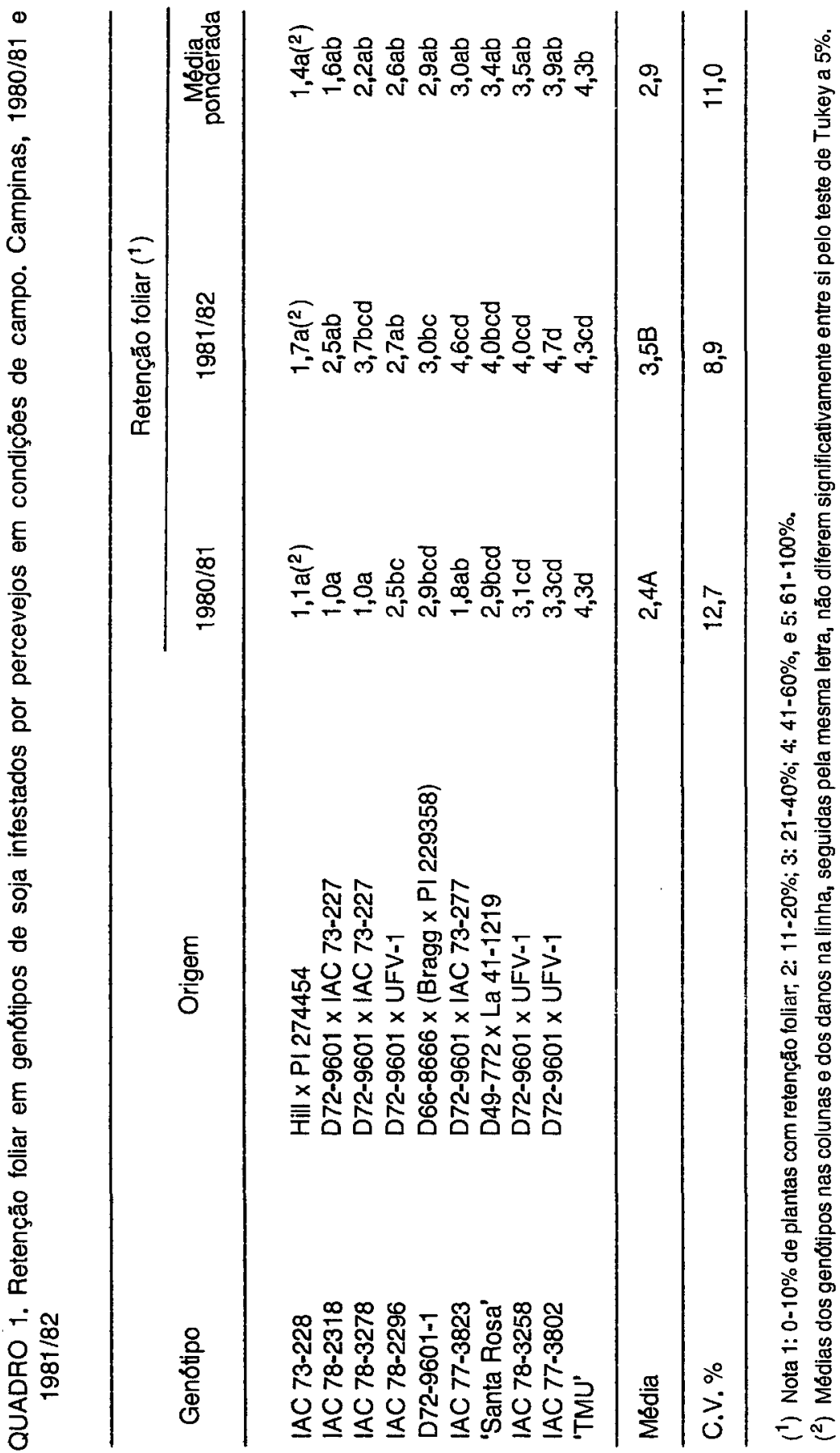


QUADRO 2. Produtividade de genótipos de soja infestados por percevejos em condições de campo. Campinas, 1980/81 e 1981/82

\begin{tabular}{llll}
\hline & & Produtividade & \\
\cline { 2 - 4 } Genótipo & $1980 / 81$ & $1981 / 82$ & $\begin{array}{c}\text { Média } \\
\text { ponderada }\end{array}$ \\
\cline { 2 - 4 } & & $\mathrm{kg} / \mathrm{ha}$ & \\
\cline { 2 - 4 } IAC 73-228 & $2011 \mathrm{ab}\left({ }^{1}\right)$ & $2393 \mathrm{a}\left({ }^{1}\right)$ & 2175 \\
IAC 78-3258 & $2327 \mathrm{a}$ & $1935 \mathrm{ab}$ & 2159 \\
IAC 78-2318 & $1963 \mathrm{ab}$ & $2140 \mathrm{a}$ & 2039 \\
'Santa Rosa' & $1970 \mathrm{ab}$ & $1987 \mathrm{ab}$ & 1977 \\
IAC 77-3802 & $2022 \mathrm{ab}$ & $1914 \mathrm{ab}$ & 1976 \\
IAC 78-2296 & $1793 \mathrm{ab}$ & $1970 \mathrm{ab}$ & 1868 \\
IAC 77-3823 & $1893 \mathrm{ab}$ & $1803 \mathrm{ab}$ & 1854 \\
IAC 78-3278 & $2095 \mathrm{ab}$ & $1518 \mathrm{ab}$ & 1848 \\
'TMU' & $1529 \mathrm{~b}$ & $2008 \mathrm{ab}$ & 1734 \\
D72-9601-1 & $1660 \mathrm{~b}$ & $921 \mathrm{~b}$ & 1343 \\
\hline Média & 1926 & 1859 & 1897 \\
\hline C.V. \% & 18,1 & 33,2 & 25,3 \\
\hline
\end{tabular}

(1) Médias seguidas pela mesma letra na coluna não diferem significativamente entre si pelo teste de Tukey a $5 \%$.

É esperado que, em áreas infestadas por percevejos, um material resistente produza mais sementes sem dano do que um suscetivel. Isso é observado no quadro 3 , onde se pode notar um gradiente entre os tratamentos na produção de grãos sem danos aparentes (classe 1). IAC 78-2318, além de apresentar o maior peso de grãos dessa classe, teve a menor quantidade de grãos não comerciáveis (classes 3 e 4). A porcentagem em peso de grãos danificados (Quadro 4), parâmetro que complementou a interpretação dos dados de classes de dano, apresentou boa precisão experimental, independente da intensidade de ataque, com os coeficientes de variação de mesma grandeza nos dois anos. Apesar de a interação ser significativa, o efeito de tratamentos suplantou o da interação, confirmando a menor perda de grãos de IAC 78-2318, seguido de IAC 73-228, reconhecidamente resistente. Novamente, verifica-se o comportamento desfavorável de D72-9601-1 e 'TMU' em relação a percevejos. 
QUADRO 3. Produtividade (peso de grãos $/ 3 \mathrm{~m}$ de linha) de genótipos de soja, separada em quatro classes de acordo com o dano causado por percevejos. Campinas, 1980/81

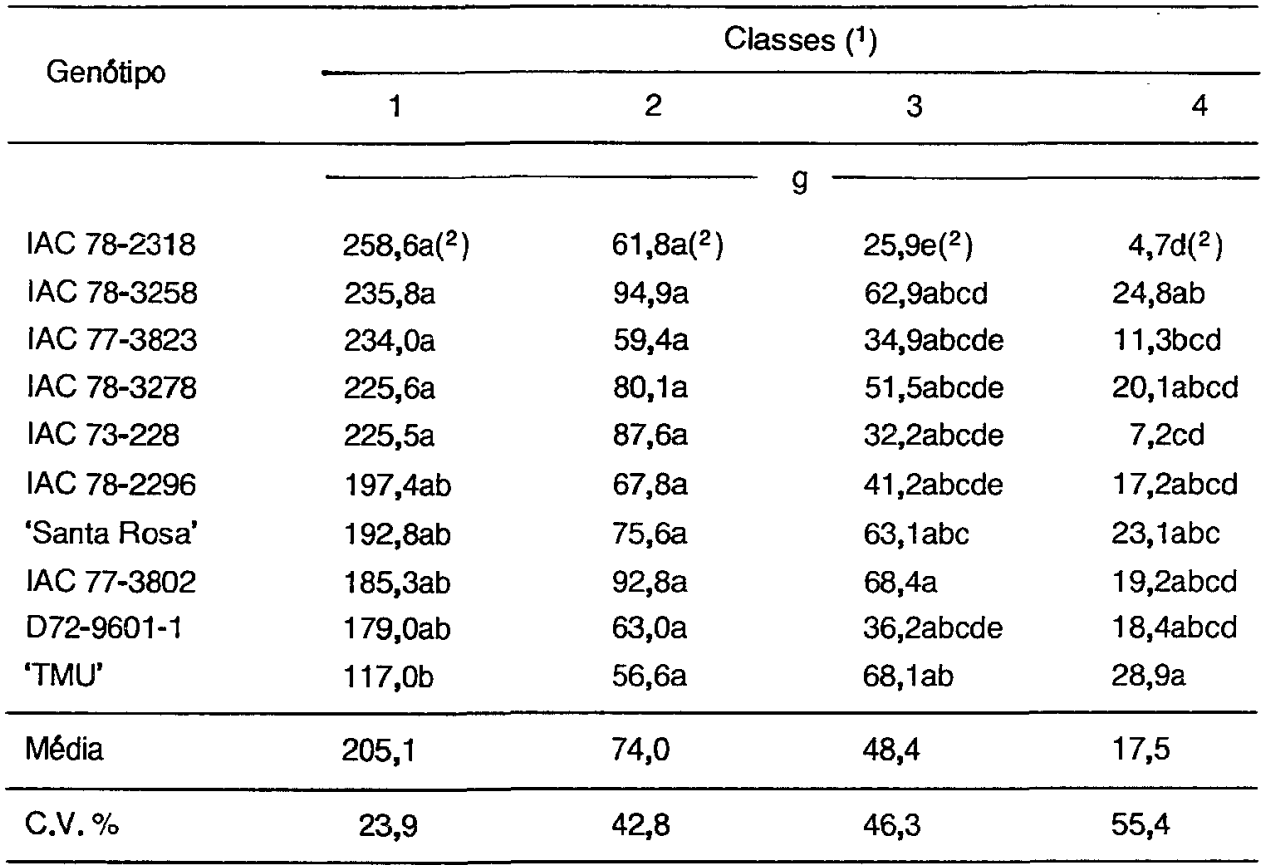

(1) 1: sementes sem danos visiveis; 2 sementes com puncturas, mas sem deformaçāo; 3: sementes com puncturas e com deformação, e 4: sementes totalmente deformadas.

(2) Médias seguidas pela mesma letra na coluna nāo diferem significativamente entre si pelo teste de Tukey a $5 \%$.

Com relação ao tamanho de sementes, foi observado por MIRANDA et al. (1979), LINK \& ESTEFANEL (1982) e LOURENÇĀO et al. (1985), que os materiais mais resistentes são possuidores de sementes pequenas e grande número de vagens, possibilitando maior número de grãos livres do ataque de percevejos. Os dados do presente estudo, resumidos no quadro 5 , confirmam essas informaçōes: IAC 73-228 e IAC 78-2318, os de melhor desempenho nos critérios usados, são os de menor peso, respectivamente 9,1 e 10,1 g por cem sementes, contrastando com D72-9601-1 e 'TMU', cujos pesos são os mais elevados. Todavia, é provável que o peso dos últimos esteja superestimado em virtude do efeito de compensação, uma vez que não havia grãos suficientes para a migração dos elaborados, acarretando aumento do peso de cem sementes. Isso é demonstrado pela significância não esperada da interação com anos, pois haveria possibilidade de alteração desse parâmetro de um ano para outro, em decorrência de condições ambientes, mas o gradiente entre cultivares deveria permanecer constante; portanto, a intensidade do ataque de percevejos interferiu provavelmente na expressão dessa característica. 
QUADRO 4. Porcentagem em peso de grãos danificados de genótipos de soja infestados por percevejos em condiçōes de campo. Campinas, 1980/81 e 1981/82

\begin{tabular}{llll}
\hline Genótipo & $1980 / 81$ & $1981 / 82$ & $\begin{array}{c}\text { Média } \\
\text { ponderada }\end{array}$ \\
\cline { 2 - 4 } IAC 78-2318 & $9,9 \mathrm{a}\left({ }^{1}\right)$ & $\%$ & \\
IAC 73-228 & $12,3 \mathrm{ab}$ & $23,8 \mathrm{a}\left({ }^{(1)}\right.$ & $15,8 \mathrm{a}\left({ }^{1}\right)$ \\
IAC 77-3823 & $16,4 \mathrm{abc}$ & $33,9 \mathrm{ab}$ & $21,6 \mathrm{ab}$ \\
IAC 78-2296 & $22,8 \mathrm{bcd}$ & $38,4 \mathrm{ab}$ & $25,8 \mathrm{abc}$ \\
IAC 78-3278 & $20,8 \mathrm{bcd}$ & $41,3 \mathrm{abc}$ & $30,7 \mathrm{abcd}$ \\
'Santa Rosa' & $29,9 \mathrm{de}$ & $45,2 \mathrm{bc}$ & $31,3 \mathrm{abcd}$ \\
IAC 78-3258 & $29,9 \mathrm{de}$ & $37,9 \mathrm{ab}$ & $33,3 \mathrm{abcd}$ \\
IAC 77-3802 & $27,2 \mathrm{~cd}$ & $47,4 \mathrm{bc}$ & $37,4 \mathrm{bcd}$ \\
D72-9601-1 & $27,9 \mathrm{~cd}$ & $54,6 \mathrm{bc}$ & $38,9 \mathrm{bcd}$ \\
'TMU' & $42,3 \mathrm{e}$ & $62,6 \mathrm{c}$ & $42,8 \mathrm{~cd}$ \\
\hline Média & $23,9 \mathrm{~A}$ & $53,9 \mathrm{bc}$ & $47,3 \mathrm{~d}$ \\
\hline C.V. \% & 18,9 & $43,9 \mathrm{~B}$ & 32,5 \\
\hline
\end{tabular}

(1) Médias dos genótipos nas colunas e dos anos na linha, seguidas pela mesma letra, não diferern significativamente entre si pelo teste de Tukey a $5 \%$.

Com exceção do 'Santa Rosa',todos os tratamentossofreram redução no teor de óleo quando a semente foi danificada pelos percevejos - Quadro 6 - fato já registrado na literatura (DAUGHERTY et al., 1964; THOMAS et al, 1974; TODD \& TURNIPSEED, 1974; GALILEO \& HEINRICHS, 1978). Em termos médios, essa diminuição atingiu $5,6 \%$. Todavia, observa-se que, apesar de resistentes a percevejos, IAC 78-2318 e IAC 73-228 apresentaram porcentagem de lipidios significativamente menor que genótipos suscetiveis, como 'TMU' e !AC 77-3802. Esse caráter desfavorável deve ser considerado num programa de melhoramento visando à resistência a percevejos em que se utitizem essas duas linhagens, ou outra fonte de resistência com essa caracteristica. Para se ter idéia da implicação do lançamento de cultivares com baixos teores de óleo, o quadro 6 traz, para cada genótipo, a produtividade média (Quadro 2) multiplicada pelo teor médio de lipidios. Verifica-se que, mesmo não havendo condições de colheita mecânica, seriam obtidas produçōes de óleo aproximadamente $12 \%$ superior para o cultivar Santa Rosa e para a linhagem IAC 78-2296, e cerca de $20 \%$ a mais para as linhagens IAC 78-3258 e IAC 78-3802 quando comparadas com a resistente (indice 100). 
QUADRO 5. Peso de cem sementes de genótipos de soja infestados por percevejos em condiçōes de campo. Campinas, 1980/81 e 1981/82

\begin{tabular}{lccc}
\hline Genótipo & $1980 / 81$ & $1981 / 82$ & $\begin{array}{c}\text { Média } \\
\text { ponderada }\end{array}$ \\
\cline { 2 - 4 } IAC 73-228 & $8,3 \mathrm{a}\left({ }^{1}\right)$ & $\mathrm{g}$ & $9,1 \mathrm{a}\left({ }^{1}\right)$ \\
IAC 78-2318 & $8,2 \mathrm{a}$ & $10,2 \mathrm{a}\left({ }^{1}\right)$ & $10,1 \mathrm{ab}$ \\
IAC 78-3278 & $10,9 \mathrm{ab}$ & $12,6 \mathrm{~b}$ & $11,8 \mathrm{abc}$ \\
IAC 77-3823 & $11,1 \mathrm{~b}$ & $12,9 \mathrm{~b}$ & $12,8 \mathrm{bc}$ \\
IAC 77-3802 & $13,4 \mathrm{bc}$ & $15,1 \mathrm{c}$ & $14,7 \mathrm{~cd}$ \\
'Santa Rosa' & $15,3 \mathrm{~cd}$ & $16,5 \mathrm{~d}$ & $17,2 \mathrm{de}$ \\
IAC 78-3258 & $16,7 \mathrm{~d}$ & $19,7 \mathrm{e}$ & $18,2 \mathrm{def}$ \\
IAC 78-2296 & $18,1 \mathrm{de}$ & $20,3 \mathrm{e}$ & $20,8 \mathrm{efg}$ \\
D72-9601-1 & $20,0 \mathrm{ef}$ & $24,4 \mathrm{~g}$ & $21,3 \mathrm{fgh}$ \\
'TMU' & $22,3 \dagger$ & $23,0 \mathrm{f}$ & $24,5 \mathrm{~h}$ \\
\hline Média & $14,4 \mathrm{~A}$ & $27,5 \mathrm{~h}$ & 16,0 \\
\hline C.V. \% & 11,7 & $18,2 \mathrm{~B}$ & 8,4 \\
\hline
\end{tabular}

(1) Médias dos tratamentos nas colunas e dos anos na linha, seguidas pela mesma letra, năo diferem significativamente entre si pelo teste de Tukey a $5 \%$.

O último critério utilizado para discriminação dos genótipos foi o poder germinativo. A influência negativa do ataque de percevejos na germinação de sementes de soja é conhecida (DAUGHERTY et al., 1964; THOMAS et al., 1974; TODD \& TURNIPSEED, 19.74; YEARGAN, 1977; GALILEO \& HEINRICHS, 1978; LINK et al., 1982), tendo sido discutida, inclusive, a importância do local da semente onde o percevejo se alimenta, o embrião ou o cotilédone, na germinação e vigor das plântulas (JENSEN \& NEWSOM, 1972). Os dados obtidos - Quadro 7 revelam, novamente, o bom desempenho de IAC 78-2318 e IAC 73-228, com os maiores indices de germinação, seguidos de 'TMU' e IAC 77-3802, que se haviam comportado, de modo geral, desfavoravelmente nos critérios anteriores.

Com base nos critérios estudados, verifica-se ter a linhagem IAC 78-2318 resistência a percevejos comparável à da IAC 78-228, constituindo nova opção para cruzamentos em programas de melhoramento de soja visando a resistência a insetos. IAC 78-2318 também foi referida como pouco danificada pela broca dos ponteiros E. aporema (LOURENÇÃO \& MIRANDA, 1983). 


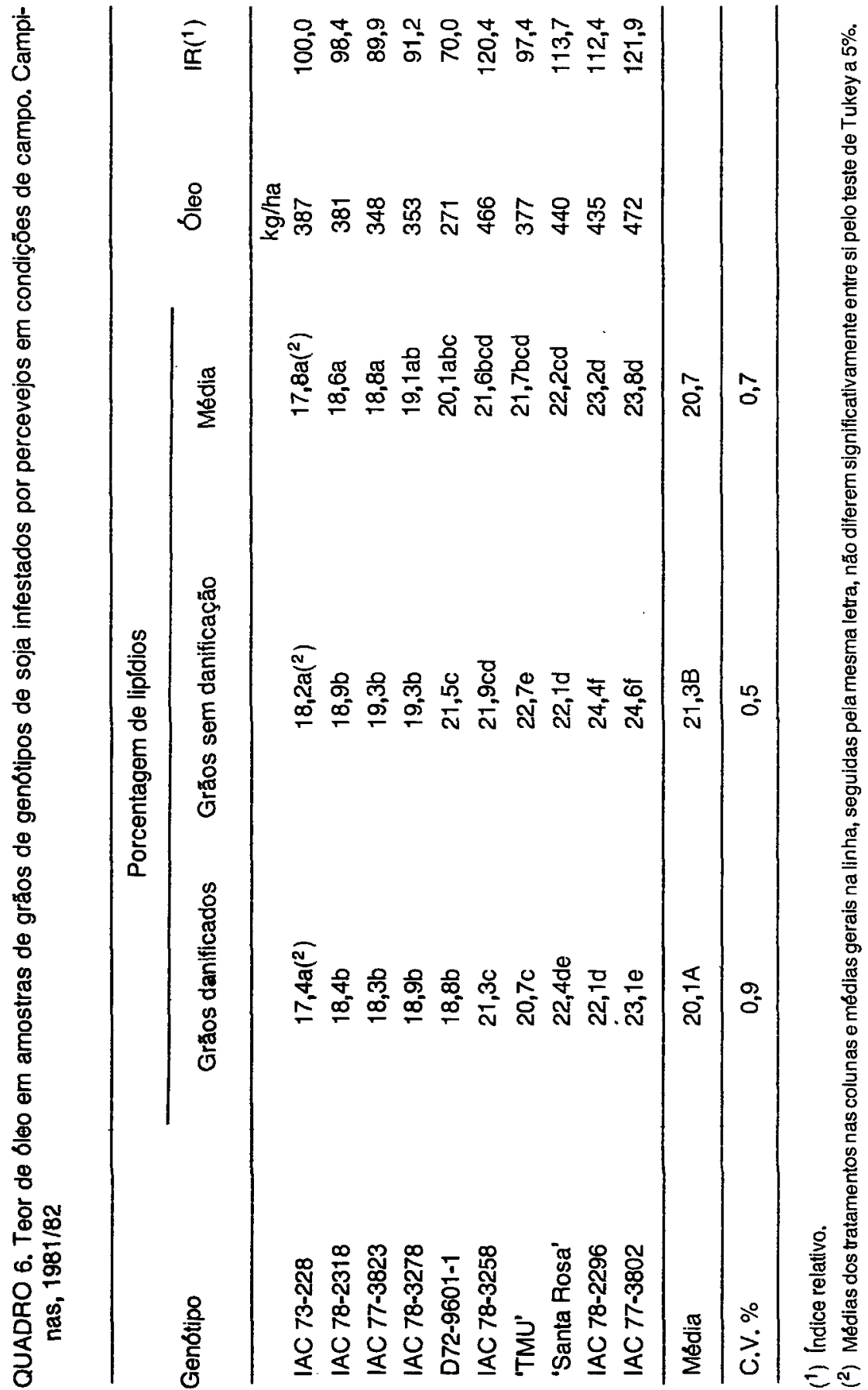


QUADRO 7. Poder germinativo de sementes de genótipos de soja submetidos à infestação de percevejos em condiçōes de campo. Campinas, 1981/82

Tratamento

Germinação

\begin{tabular}{ll}
\hline IAC 78-2318 & $\%$ \\
IAC 73-228 & $75,3 \mathrm{a}\left({ }^{(1)}\right.$ \\
'TMU' & $70,7 \mathrm{ab}$ \\
IAC 77-3802 & $66,3 \mathrm{abc}$ \\
IAC 78-3258 & $63,0 \mathrm{abc}$ \\
IAC 78-3278 & $57,0 \mathrm{abc}$ \\
'Santa Rosa' & $54,7 \mathrm{abc}$ \\
IAC 77-3823 & $51,7 \mathrm{bc}$ \\
IAC 78-2296 & $51,0 \mathrm{bc}$ \\
D72-9601-1 & $46,3 \mathrm{~cd}$ \\
\hline Média & $28,7 \mathrm{~d}$ \\
\hline C.V. \% & 56,5 \\
\hline
\end{tabular}

(†) Médias seguidas pela mesma letra não diferem significativamente entre si pelo leste de Tukey a $5 \%$.

Outro aspecto importante é a constatação da suscetibilidade a percevejos em D72-9601-1, material resistente a lagartas e, em função disso, de valor no melhoramento da soja. Todavia, sua suscetibilidade, que pode ter sido agravada pelo seu ciclo mais precoce, não deve ser considerada limitante, pois IAC 78-2318 descende dela (Quadro 1).

As relações entre critérios - Quadro 8 - auxiliam o entendimento das associaçōes entre características e resistência a percevejos. A produtividade esteve correlacionada negativamente com o peso de cem sementes e com a porcentagem em peso de grãos danificados, porém não esteve associada à retenção foliar, o que talvez se deva ao baixo índice de retenção no primeiro ano. A correlação significativa entre retenção e porcentagem em peso de grãos danificados ratifica o acerto do procedimento de se selecionar para maturação normal (ausência de retenção) no programa de melhoramento. As significâncias obtidas entre peso de cem sementes $(+0,82)$ e teor de óleo $(+0,56)$ em relação à porcentagem em peso de grãos danificados fortalecem a hipótese de que essas duas características estejam relacionadas com mecanismos de resistência a percevejos em soja. A resistência conferiu maior germinação, que está correlacionada negativamente com a porcentagem em peso de grãos danificados $(-0,57)$, fato a ser ressaltado diante das dificuldades de produção de sementes de boa qualidade em nossas condições. 
QUADRO 8. Valores do coeficiente de correlação linear simples ( $r$ ) de porcentagem em peso de grãos danificados com produção, retenção foliar, peso de cem sementes, porcentagem de germinaçăo e teor de óleo; peso de cem sementes com produção e retenção foliar; e de retenção foliar com produção, obtidos em genótipos de soja infestados por percevejos em condições de campo. Campinas, 1980/81 e 1981/82

\begin{tabular}{lccc}
\hline & $\begin{array}{c}\text { Retenção } \\
\text { foliar }\end{array}$ & $\begin{array}{c}\text { Peso de } \\
\text { cem sementes }\end{array}$ & $\begin{array}{c}\text { Porcentagem } \\
\text { em peso de grãos } \\
\text { danificados }\end{array}$ \\
\hline $\begin{array}{l}\text { Produção } \\
\text { Retenção foliar }\end{array}$ & $-0,26$ n.s. & $-0,56^{\star}$ & $-0,56^{\star}$ \\
Peso de cem sementes & $0,69^{\star \star}$ & $0,83^{\star \star}$ \\
Porcentagem de germinação & & $0,82^{\star \star}$ \\
Teor de óleo & & $-0,57^{\star}$ \\
\hline
\end{tabular}

n.s.: Não significativo. *: Significativo ao nivel de $5 \%$ pelo testet. **: Significativo ao nivel de $1 \%$ pelo teste $t$.

\section{SUMMARY}

\section{RESISTANCE OF SOYBEAN TO INSECTS. VII. EVALUATION OF DAMAGE TO CULTIVARS AND LINES BY STINK BUGS}

During the seasons of $1980 / 81$ and $1981 / 82$, the performance of eight soybean lines (IAC 73-228, IAC 77-3802, IAC 77-3823, IAC 78-2296, IAC 78-2318, IAC 78-3258, IAC 78-3278 and D72-9601-1) and two cultivars (Santa Rosa and TMU) was evaluated in relation to the attack of stink bugs in the field, at Campinas, State of São Paulo, Brazil. In the season of 1980/81, the low natural infestation of Piezodorus guildinii (West.) and Nezara viridula (L.) was supplemented by liberation of Euschistus heros (Fabr.) adults collected on soybean crops; in the following season, the high natural infestation was sufficient to cause severe damage to soybeans. Seven criteria of damage evaluation were utilized: foliar retention, yield, yield divided in four damage classes, percentage of the damage grain weight, weight of hundred seeds, oil content and germination percentage. The line IAC 73-228 confirmed its resistance and the same performance was observed for the IAC 78-2318. Nevertheless, both these lines have as unfavourable characteristics, small seeds and low oil content.

Index terms: soybean; Glycine max (L.) Merrill; stink bugs resistance; Pentatomidae; Nezara viridula (L.); Piezodorus guildinii (West); Euschistus heros (Fabr.). 


\section{REFERÊNCIAS BIBLIOGRÁFICAS}

DAUGHERTY, D.M.; NEUSTADT, M.H.; GEHRKE, C.W.; CAVANAH, L.E.; WILLIAMS, L.F. \& GREEN, D.E. An evaluation of damage to soybeans by brown and green stink bugs. Journal of Economic Entomology, 57(5):719-722, 1964.

GALILEO, M.H.M. \& HEINRICHS, E.A. Avaliaçāo dos danos causados por Piezodorus guildinii (Westwood, 1837) (Hemiptera, Pentatomidae) em diferentes niveis e épocas de infestação, na qualidade da semente de soja (Glycine max (L.) Merrill). Anais da Sociedade Entomológica do Brasil, Jaboticabal, 7(2):75-88, 1978.

GILMAN, D.F.; MCPHERSON, R.M.; NEWSOM, L.D.; HERZOG, D.C. \& WILLIAMS, C. Resistance in soybeans to the southern green stink bug. Crop Science, 22:573-576, 1982.

JENSEN, R.L. \& NEWSOM, L.D. Effect of stink bug-damaged soybean seeds on germination, emergence and yield. Journal of Economic Entomology, 65(1):261-264, 1972.

JONES JR., W.A. \& SULLIVAN, M.J. Soybean resistance to the southern green stink bug, Nezara viridula. Journal of Economic Entomology, 72(4):628-632, 1979.

LINK, D. \& ESTEFANEL, V. Influência do número de sementes por legume e de legumes por planta sobre o nivel de dano de pentatomideos em soja. Revista do Centro de Ciências Rurais, Santa Maria, 12(2-3):109-113, 1982.

; FEDERIZZI, L.C. \& RUEDELL, J. Efeito do ataque de pentatomideos na qualidade de sementes de soja. Revista do Centro de Ciências Rurais, Santa Maria,12(2-3):93$-102,1982$.

LOURENÇĀO, A.L. \& MIRANDA, M.A.C. de. Resistência de soja a insetos. l. Comportamento de linhagens e cultivares em relação a Epinotia aporema (Wals.) (Lepidoptera:Torticidae). Bragantia, Campinas, 42:203-209, 1983.

;ROSSETTO, C.J. \& MIRANDA, M.A.C. de. Resistência de soja a insetos. III. Seleção de linhagens resistentes a percevejos. Bragantia, Campinas, 44(1):77-86, 1985.

MIRANDA, M.A.C. de; ROSSETTO, C.J.; ROSSETTO, D.; BRAGA, N.R.; MASCARENHAS, H.A.A. \& MASSARIOL, A. Resistência de soja a Nezara viridula (L.) e Piezodorus guildinii (Westw.) em condiçōes de campo. Bragantia, Campinas, 38:181-188, 1979.

PANIZZI, M.C.C.; BAYS, I.A.; KIIHL, R.A.S. \& PORTO, M.P. Identificação de genótipos fontes de resistência a percevejos-pragas da soja. Pesquisa Agropecuária Brasileira, Braslia, 16(1):33-37, 1981.

ROSSETTO, C.J.; IGUE, T.; MIRANDA, M.A.C. de \& LOURENÇĀO, A.L. Resistência de soja a insetos: VI. Comportamento de genótipos em relação a percevejos. Bragantia, Campinas, 45(2):323-335, 1986.

THOMAS, G.D.; IGNOFFO, C.M.; MORGAN, C.E. \& DICKERSON, W.A. Southern green stink bug: influence on yield and quality of soybeans. Journal of Economic Entomology, 67(4):501-503, 1974.

TODD, J.W. \& TURNIPSEED, S.G. Effects of southern green stink bug damage on yield and quality of soybeans. Journal of Economic Entomology, 67(3):421-426, 1974.

YEARGAN, K.V. Effects of green stink bug damage on yield and quality of soybeans. Journal of Economic Entomology, 70(5):619-622, 1977. 